\title{
Endometriosis of the colon
}

\author{
M. MichOWITZ* \\ M.D. \\ B. HAMMAR \\ F.R.C.S. \\ I. LAZAROVICI \\ M.D. \\ M. SolowIEJCZYK \\ M.D.
}

*Department of Surgery, Ichilov Medical Center, and $\dagger$ The Sackler School of Medicine, Tel-Aviv University, Israel

\begin{abstract}
Summary
A case of endometriosis of the colon is presented. The incidence, symptomatology and treatment are discussed.

\section{Introduction}

Endometriosis is defined as the existence of endometrial tissue separate from the uterus. Most of the reported cases of endometriosis are in the true pelvis. The clinical presentation is usually lower abdominal pain which is aggravated in the pre-menstrual period as this tissue is under the hormonal influence of the ovaries. Other manifestations are mainly gynaecological such as menstrual irregularities, dysmenorrhoea and dyspareunia (Novak, Jones and Jones, 1975).

Endometriosis of the large bowel is one of the rarest causes of intestinal obstruction (Ponka, Brush and Hodgkinson, 1973). The authors present a case of endometriosis of sigmoid colon which caused chronic large bowel obstruction.
\end{abstract}

\section{Case report}

One year before admission, a married female aged 31 years and nulliparous started to suffer from progressive constipation, relieved by taking increasing amounts of laxative.

In the past, because of primary sterility and after basic gynaecological investigations which included hysterography, laparoscopy and trial of hormonal treatment, she underwent laparotomy because of a uterine myoma which was partly obstructing the Fallopian tubes. At laparotomy, a firm tumour was palpated in the wall of the sigmoid colon, $4 \mathrm{~cm}$ in diameter and partly obstructing the lumen. Exploration of the rest of the abdomen did not reveal any further abnormalities. The uterine myoma was removed and it was decided to defer a second operation, excision of the sigmoid lesion, on account of inadequate bowel preparation. Post-operative recovery was uneventful.

Examination on the present admission, showed $\stackrel{\omega}{\oplus}$ that the general condition was good, although the윽 patient was thin and small, weight $40 \mathrm{~kg}, \mathrm{BP}-$ $100 / 70 \mathrm{mmHg}$, pulse rate 84 .

Barium enema showed an eccentric intramurak tumour partly obstructing the lumen. The mucosa $\vec{\circ}$ appeared normal (Fig. 1).

At colonoscopy, the instrument was inserted to $40 \mathrm{~cm}$ without any abnormal findings; it wit? impossible to pass beyond this level. At operation, there was a long, redundant sigmoid with a firm tumour, $4 \mathrm{~cm}$ in diameter, in the wall of the sigmoid, $\stackrel{\varrho}{\mathbb{Q}}$ obstructing the bowel lumen and an obvious chocolate cyst was found on the peritoneal surface. Theô affected segment was resected (Figs 2, 3) and end-toend anastomosis performed. The postoperative course was uneventful.

The histological picture showed a localized area윽 of endometrial tissue bearing characteristic glands, stroma and occasionally smooth muscle.

\section{Discussion}

Endometriosis is most frequently described as occurring in the vicinity of the uterus. The incidence, in decreasing order, is mainly in the ovary, Fallopian tubes, utero-ovarian ligament, recto-vaginal septum, utero-sacral ligament, round ligament, rectus ab- $-\infty$ dominis muscle, the umbilicus and bowel (Gray, N 1973).

Reports on the incidence of endometriosis vary. $\frac{\omega}{\sigma}$ During the reproductive period its prevalence is said to be $8-15 \%$ of all women; of those women found to have endometriosis, the bowel is affected in $12-34 \%$ (Jenkinson and Brown, 1943; Kratzer and Salvati, 1955; Davis and Trueheart, 1964). Other reports state that the condition is much rarer than $\mathbb{\Phi}$

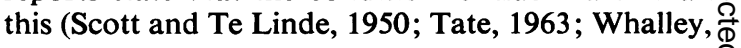




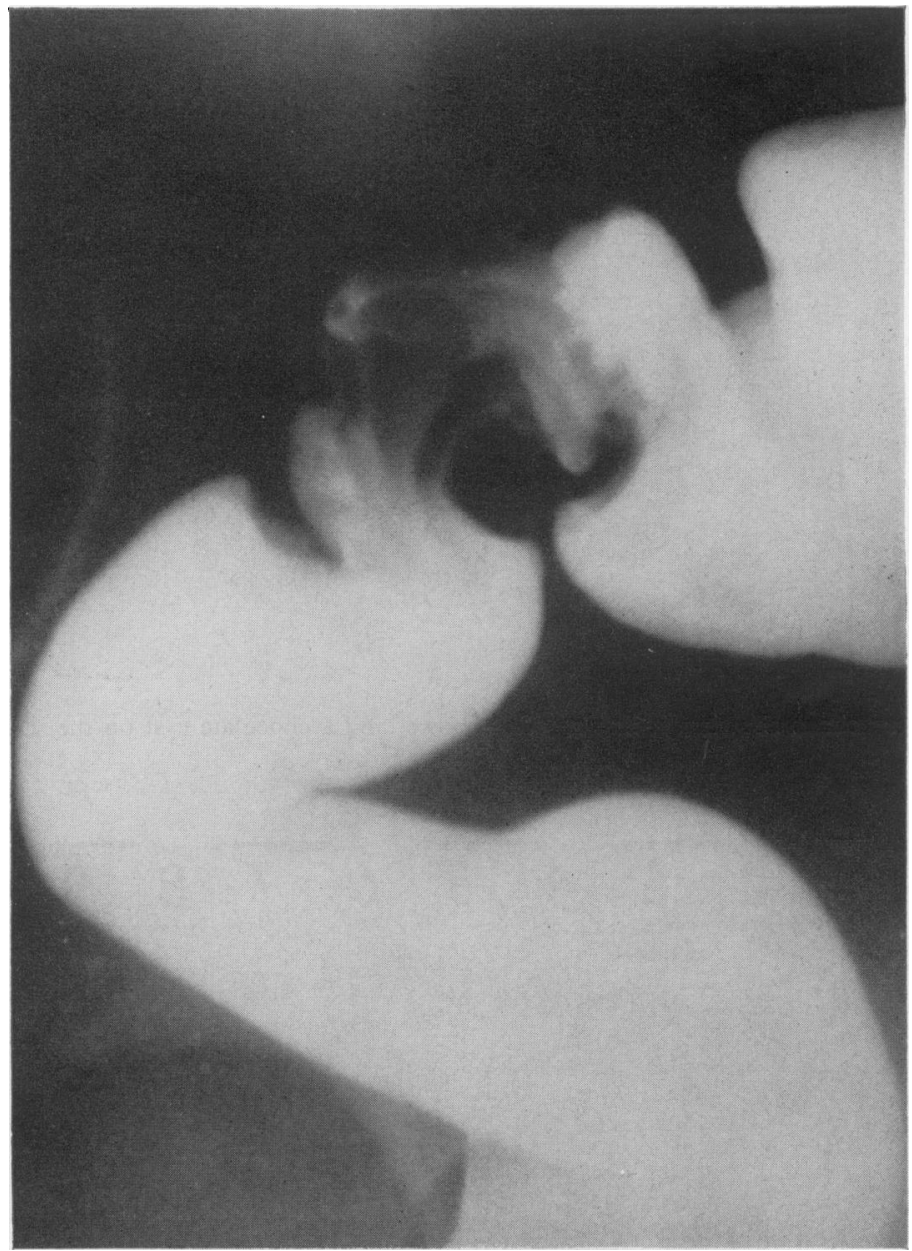

FIG. 1. Barium enema showing the normal mucosa at the site of the lesion.

1967). In spite of this apparent frequency, few of the patients suffer from bowel symptoms because the endometrial implants are serosal. Constrictive lesions or bleeding from intramural or mucosal endometrioma are rare (Haubrich, 1976). In the case presented the endometrioma was intramural and there were also a few small chocolate cysts in the serosa and mucosa (Fig. 3).

Endometriosis occurring in the bowel may affect the appendix, rectosigmoid, caecum and lower ileum. No case has been recorded as occurring in the transverse colon (Gray, 1973).

Endometriosis of the bowel presents with lower abdominal pain especially pre-menstrually, and disturbances of bowel movements, mainly constipation but occasionally diarrhoea and tenesmus. Rectal bleeding may rarely occur. Bowel obstruction is the most common intestinal complication, both in the large and small bowel, as in this case. The mechanism in the large bowel is circumferential fibrosis, and in the small bowel kinking of the bowel or its mesentery; other mechanisms are intussusception or volvulus (Davis and Trueheart, 1964; Wynn, 1971; Ponka et al., 1973).

Barium enema may show a localized eccentric constricting lesion. The main differentiation from carcinoma is that the mucosal pattern remains normal in the affected area in endometriosis (Fig. 1) (Lesh and Hathcock, 1955; Johnson, Coppola and Moll, 1957; Hauck, 1960). Most cases are incidentally diagnosed at laparoscopy or laparotomy carried out for investigation of sterility or other gynaecological reasons, as was the case in the present patient. 


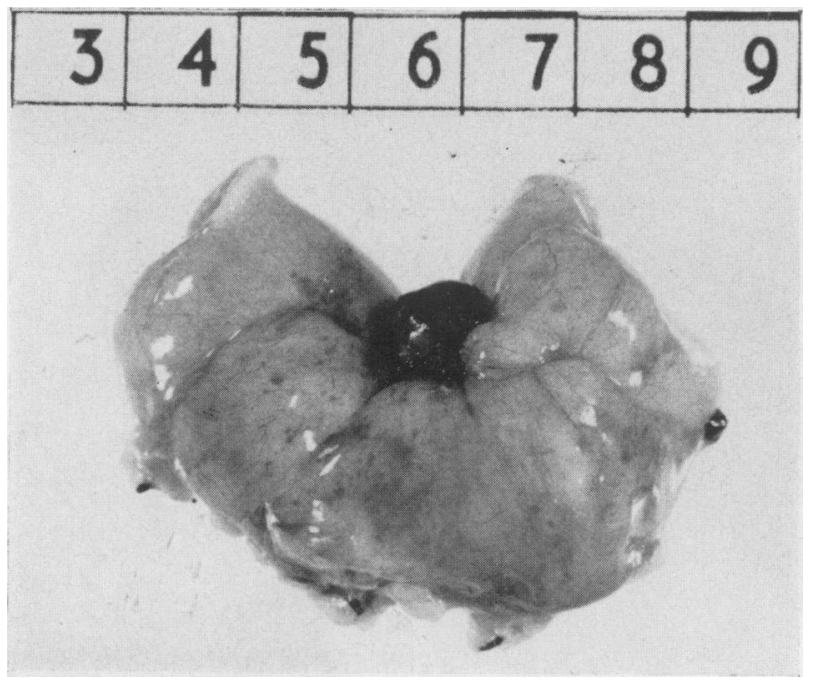

FIG. 2. Operation specimen showing puckering of the bowel and a chocolate cyst on the serosal surface (scale in $\mathrm{cm}$ ).

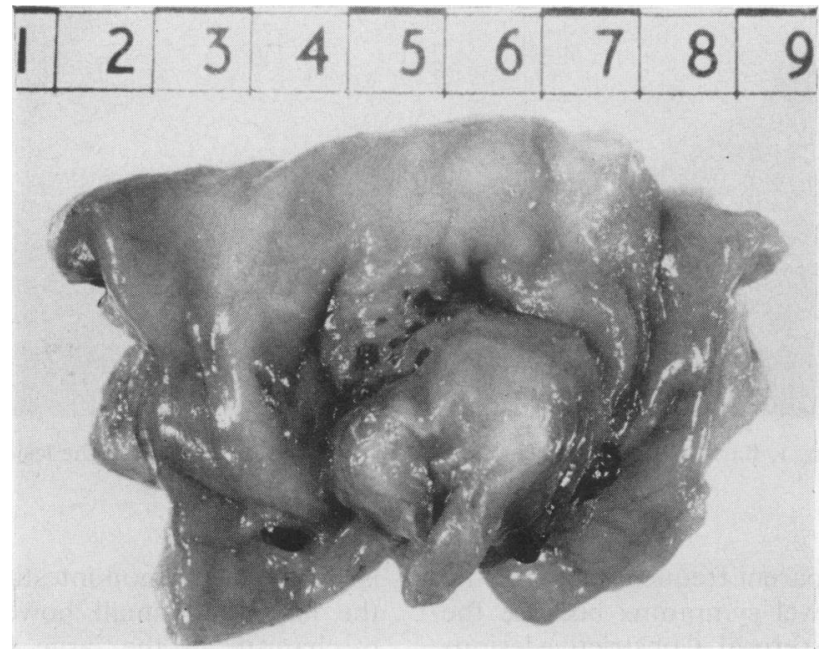

Fig. 3. Operation specimen showing elevation of intact mucosa by the lesion plus a number of small chocolate cysts $($ scale in $\mathrm{cm}$ ).

Endometrial tissue responds to hormones with aggravation of symptoms by oestrogens, improvement after oophorectomy or at the menopause and improvement under treatment with progesterone or during pregnancy (Novak et al., 1975; Rakoff, 1976).

In spite of these facts, hormonal treatment alone is not sufficient for bowel lesions; in cases with obstructive symptoms complete excision of the affected segment is the treatment of choice. Occasionally it may be possible to resect the endometrioma alone without entering the bowel lumen (Davis and Trueheart, 1964; Gray, 1973). In the present case, ass there was a single localized lesion and because of the patient's relative youth, resection of the lesion alone was performed.

\section{References}

Davis, C. \& Trueheart, R. (1964) Surgical management of endometrioma of the colon. American Journal of Obstetric and Gynecology, 89, 453. 
GraY, L.A. (1973) Endometriosis of the bowel: Role of bowel resection, superficial excision and oophorectomy in treatment. Annals of Surgery, 177, 580.

HAUBRICH, W.S. (1976) Enteric endometriosis. In: Gastroenterology, Vol. II (Ed by Bockus, H.L.), pp. 1107-1112. W. B. Saunders Company, Philadelphia, London and Toronto.

Hauck, A.E. (1960) Endometriosis of the colon. Annals of Surgery, 151, 896.

Jenkinson, E.L. \& Brown, W.H. (1943) Endometriosis: A study of 117 cases with specific reference to constricting lesions of rectum and sigmoid colon. Journal of the American Medical Association, 122, 349.

Johnson, C.G., Coppola, A.F. \& Moll, C.F. (1957) Complications of endometriosis of the sigmoid colon. Southern Medical Journal, 50, 893.

Kratzer, G.L. \& Salvati, E.P. (1955) Collective review of endometriosis of the colon. American Journal of Surgery, 90, 866.

LeSH, R.E. \& HathCOCK, A.H. (1955) Endometriosis of the rectum. Obstetrics and Gynecology, 5, 320.
Novak, E.R., Jones, G.S. \& Jones, H.W. (1975) Endometriosis. In: Novak's Textbook of Gynecology, 9th edn, pp. 542-565. Williams \& Wilkins Company, Baltimore.

Ponka, J.L., Brush, B.E. \& Hodgkinson, C.P. (1973) Colorectal endometriosis. Diseases of the Colon and Rectum, 16, 490.

RakofF, A.E. (1976) The gonads. In: Gastroenterology, Vol. IV (Ed by Bockus, H.L.), pp. 399-400. W. B. Saunders Company, Philadelphia, London and Toronto.

ScotT, R.B. \& TE LINDE, R.W. (1950) External endometriosis - the scourge of the private patient. Annals of Surgery, 131, 697.

TATE, G.T. (1963) Acute obstruction of the large bowel due to endometriosis. British Journal of Surgery, 50, 771.

Whalley, R.C. (1967) Endometriosis of the colon. British Journal of Surgery. 54, 805.

WYNN, T.E. (1971) Endometriosis of the sigmoid colon. Massive intramural hematoma. Archives of Pathology, 92, 24. 